\title{
Modulatory effects of green tea and aloe vera extracts on experimentally-induced lung fibrosis in rats: histological and immunohistochemical study
}

\author{
Mohamed Y. Salem, Nahla El-Eraky El-Azab and Eman M. Faruk* \\ *Correspondence: faruk_eman@yahoo.com

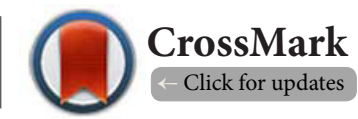

Department of Histology and Cell Biology, Benha Faculty of Medicine, Benha University, Egypt.

\begin{abstract}
Background: Pulmonary fibrosis (PF) is a multifactorial disease in the human. The existing therapeutic agents display unfavorable adverse effects. Consequently, the discovery of novel therapeutic agents for the prevention and treatment of PF remains a challenge.

Aim of the work: Evaluation of the modulatory effect of green tea and aloe vera (AV) extracts on bleomycin induced pulmonary fibrosis in rats.

Material and methods: Fifty adult male rats were utilized and divided equally into 5 groups. The first was served as control group, the second was the bleomycin (BLM) group (daily I.P. dose $10 \mathrm{mg} / \mathrm{kg}$ body weight for 10 days), the third was the green tea (GTE) group which was given daily oral dose of GTE (150 mg/ $\mathrm{kg}$ b.w.) for 14 days with concomitant IP administration of BLM for 10 consecutive days, the fourth was the Aloe vera (AV) group which was given daily oral dose of AV (300 mg/kg b.w.) for 14 days with concomitant IP administration of BLM for 10 consecutive days, the fifth was the GTE and AV group. Lung samples were taken 14 days after the treatment. Paraffin sections were prepared for histological; H\&E and Masson's trichrome staining and immunohistochemical study.

$\underline{\text { Results: }}$ Green tea group revealed normal bronchioles, alveoli with apparently thin interalveolar septa, few cellular infiltration and extravasated RBCs and induced a significant decreased $(\mathrm{P} \leq 0.05)$ in collagen fibers accumulation and in caspase-3 expression compared with BLM group. Group IV (AV) and group V (GTE and AV) revealed alveoli with apparently thicker interalveolar septa, more cellular infiltration, congested blood vessels and extravasated RBCs in comparison with GTE group. Group IV showed insignificant decreased $(\mathrm{P} \leq 0.05)$ in collagen fibers accumulation compared with BLM group while the decrease was significant in caspase-3 expression. Group V showed insignificant decreased $(\mathrm{P} \leq 0.05)$ in collagen fibers accumulation and in caspase-3 expression compared with BLM group.
\end{abstract}

Conclusion: Green tea and aloe vera partially alleviate pulmonary fibrosis induced by bleomycin in rats. Supporting the potential benefits of using aloe vera and green tea as a potential novel therapeutic agents by diet.

Keywords: GTE, AV, blood vessels, pulmonary fibrosis

\section{Introduction}

There is a global resurgence of interest in herbal medicine. The importance of botanicals and herbals is becoming recognized by developed countries. The use of complementary or alternative medicine has increased tremendously in the West, with more and more countries believing in its benefits, which is now regulting and licensing the sale of herbal products into their countries [1].

Green tea, a product of the dried leaves of Camellia sinensis, is the most widely consumed beverage in the world with no 
Salem et al. Journal of Histology \& Histopathology 2014,

http://www.hoajonline.com/journals/pdf/2055-091X-1-6.pdf

known serious side effects [2]. Green tea is being widely studied for its beneficial effect in the treatment and prevention of human diseases. It is considered to be antiinflammative, antioxidative, antimutagenic and anticarcinogenic and can prevent cardiac disorders [3]. Green tea polyphenols have demonstrated significant antioxidant, anticarcinogenic, antiinflammatory, thermogenic and antimicrobial properties in numerous human, animal, and in vitro studies [4].

Aloe vera L. (Syn.: Aloe barbadensis Miller) is a cactus-like perennial plant belonging to family Liliaceae (sub-family of the Asphodelaceae), native to North Africa and cultivated in warm climatic areas [5]. Aloe vera (AV) consists of high content of phenolic compounds, glycosides (aloins), 1,8-dihydroxyanthraquinone derivatives (aloe emodin), beta-1,4 acetylated mannan, mannose-phosphate and alprogen glucoprotein [6]. Recent scientific investigations on medicinal properties of $A V$ made it worldwide novel valuable ingredient for food, cosmetic and pharmaceutical industry [7]. Leaf exudates and mucilaginous gel of Aloe possesses anti-inflammatory, antioxidant, antifungal, antibacterial, anti-arthritic, antirheumatoid [8], anticancer [9], cytoprotective, cardiac stim-ulatory and immunomodulatory activities [10]. It is used to protect against gastric ulceration, remedy against a variety of skin disorders, promotes wound healing [11].

Pulmonary fibrosis is the end-stage of a group of chronic diseases categorized as idiopathic interstitial pneumonias [12]. An increasing number of people are affected by pulmonary fibrosis worldwide, with increasing morbidity and mortality rates [13]. Multiple factors, including transforming growth factor (TGF)-b1, connective tissue growth factor (CTGF), platelet-derived growth factor (PDGF), inflammatory cytokines, chemokine (C-C motif) ligand 2/monocyte chemo attractant protein-1 (CCL2), have been implicated in the pathogenesis of pulmonary fibrosis [4]. Currently, strong evidence proves that cellular redox state and oxidant/antioxidant balance play important roles in the pathogenesis of pulmonary fibrosis [15]. Oxidative stress induces structural cell apoptosis and up regulates proinflammatory cytokine synthesis. Dysregulations in the balance of some growth factors induced by oxidative stress possibly play major roles in distinguishing between normal and pathologic tissue repair [13]. Lung fibrosis develops in a number of clinical diseases, including interstitial lung diseases and idiopathic interstitial pneumonias, as part of several systemic connective tissue diseases and childhood interstitial lung disease syndromes, and in response to many types of lung injury, including radiation and some chemotherapeutic drugs. Initial therapies focused on aggressive anti-inflammatory treatment; however, this approach has not improved loss of lung function or survival. Currently, there are no approved medical antifibrotic therapies for pulmonary fibrosis [16].

The aim of the present study was to evaluate, the modulatory effect of green tea and AV extracts on bleomycin induced pulmonary fibrosis in rats.

\section{Materials and methods}

In this study, 50 adult male albino rats of average weight 150 $200 \mathrm{~g}$ were used. The animals obtained from the animal house, Moshtohor faculty of Veterinary Medicine, Benha University Moshtohor city Egypt. Strict care and cleaning measures were utilized to keep the animal in a normal healthy state; the animals were kept in animal cages under the prevailing atmospheric conditions. They were kept on normal balanced diet and tap water. All ethical protocols for animal treatment were followed and were supervised by the animal facilities. All animal experiments received approval from the Institutional Animal Care Committee.

Bleomycin sulfate (Merck Millipore, MA, United States) was purchased from NOOR SCIENTIFIC \& TRADE (8 El Noor St, Shoubra El Khaema, Kaliobyea, Egypt). Bleomycin (BLM) dissolved in normal saline and was given intraperitoneal (IP) in a dose of $10 \mathrm{mg} / \mathrm{kg} /$ day $/ 10$ days) to induce lung fibrosis [17]. Green tea extract (GET) was obtained from Technomade Group (Nasr City, Cairo, Egypt) as 350 gm powdered extract. It was freshly dissolved in distilled water before administration by gastric tube at a dose of $150 \mathrm{mg} / \mathrm{kg}$ b.w. [18].

\section{Preparation of Aloe vera extract}

$A V$ solid gel in the center of the leaf was collected and homogenized resulting mucilaginous, thick and straw colored homogenate was obtained and lyophilized. Then the lyophilized sample was extracted using $95 \%$ ethanol. The filtrate was collected and evaporated to dryness under reduced pressure in a rotary evaporator at $60^{\circ} \mathrm{C}$. The residue was stored in dry sterilized small containers at $4^{\circ} \mathrm{C}$ until further use. The drug solutions were prepared freshly each time. The dosing schedule used was once per day. The extracts were administered orally daily to rats by gastric tube at a dose of $300 \mathrm{mg} / \mathrm{kg}$ b.w. [19].

\section{Experimental procedure}

The rats were divided into four groups of 10 animals in each group ( $n=10)$ as follows.

\section{Group I}

normal control rats.

\section{Group II (BLM group)}

BLM induced pulmonary fibrosis rats.

\section{Group III (green tea group)}

Rats were given daily oral dose of GTE for 14 days with concomitant IP administration of BLM for 10 consecutive days.

\section{Group IV (AV group)}

Rats were given daily oral dose AV leaf gel extract for 14 days with concomitant IP administration of BLM for 10 consecutive days.

\section{Group V (green tea and AV group)}

Rats were given daily oral dose of GTE and AV leaf gel extract for 14 days with concomitant IP administration of BLM for 10 consecutive days. 
Salem et al. Journal of Histology \& Histopathology 2014,

http://www.hoajonline.com/journals/pdf/2055-091X-1-6.pdf

After 14 days of the treatment, the fasted rats were sacrificed. A small portion of lung was fixed in $10 \%$ formalin for H\&E and Masson's trichrome staining [20] and immunohistochemical detection of caspase- 3 using a standard avidin-biotin peroxidase complex system according to the kit used (Neomarkers) followed by diaminobenzidine (DAB) visualization [21]. Sections were counterstained with hematoxylin [22].

\section{Morphometric study}

The mean area percentage of collagen fibers accumulation and of caspase- 3 expression were quantified in 10 images for each group using Image-Pro Plus program version 6.0 (Media Cybernetics Inc., Bethesda, Maryland, USA). Collagen fibers accumulation and caspase-3 expression in group III, IV and $V$ compared with group II (affected group) using the t-test, with $\mathrm{P}<0.05$ as the level of statistical significance. Statistical analyses were carried out using IBM SPSS Statistics software for Windows, Version 20 (IBM Corp., Armonk, NY, USA).

\section{Results \\ H\&E}

The control group showed normal histological architecture of lung with many alveoli, alveolar sac, alveolar ducts, bronchioles, blood vessels (Figure 1A) and thin interalveolar septum (Figure 1B). The group II (BLM group) showed lung bronchioles, alveoli with thick interalveolar septa encroaching on alveoli (collapsed alveoli), cellular infiltration, dilated congested blood vessels and extravasated red blood cells (RBCs) (Figure 1C). Sections of group III (green tea group) revealed bronchioles, alveoli with apparently thin interalveolar septa, few cellular infiltration and extravasated RBCs (Figure 1D). In sections of Group IV (AV group) revealed alveoli with apparently thicker interalveolar septa, more cellular infiltration, congested blood vessels and extravasated RBCs in comparison with green tea group (Figure 1E). In sections of Group V (green tea and AV group) lung architecture, alveoli, thick interalveolar septa, cellular infiltration and congested blood vessels appeared near to those of the BLM group (Figure 1F).

\section{Masson trichrome}

The control group showed very thin collagen fibers around alveoli or within the interalveolar septa (Figure 2A). The BLM group showed extensive accumulation of collagen fibers around alveoli or within the interalveolar septa (Figure 2B). The green tea group showed minimal accumulation of collagen fibers in interalveolar septa (Figure $\mathbf{2 C}$ ) while collagen fibers accumulation was moderate in AV group (Figure 2D) Group $\mathrm{V}$ (green tea and AV group) showed marked accumulation of collagen fibers around alveoli or within the interalveolar septa (Figure 2E).

\section{Immunohistochemical study}

Positive immunohisto-chemical staining of caspase-3 demonstrated as brown cytoplasmic staining (index for the degree

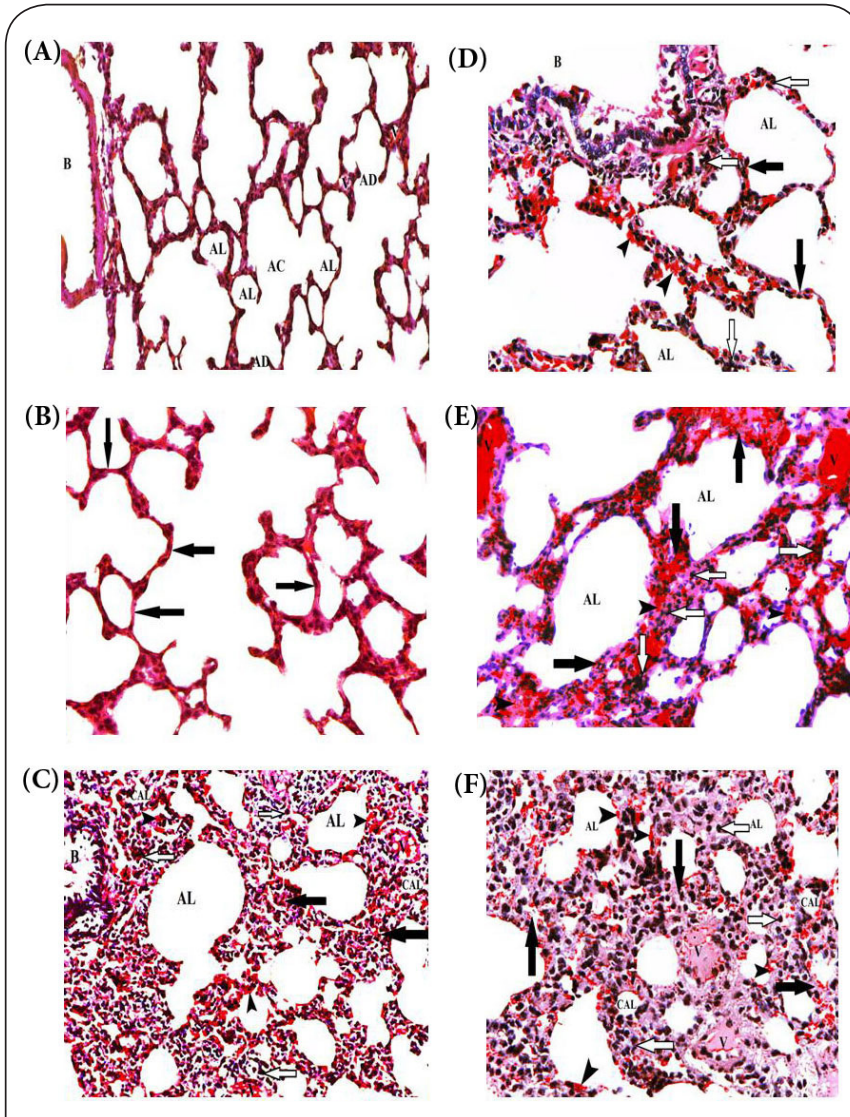

Figure 1. Photomicrograph of a section in rat lung according to $H \& E$.

(A) Group I (control group) showing many alveoli (AL), alveolar sacs (AC), alveolar ducts (AD), bronchioles (B) and blood vessels (V). [H\&E, X 200].

(B) Group I (control group) showing thin interalveolar septa (black arrow). [H\&E, X 400].

(C) Group II (BLM group) showing a bronchiole (B) and alveoli (AL) with thick interalveolar septa (black arrow), cellular infiltration (white arrow), extravasated RBCs (arrow head). Many collapsed alveoli (CAL) and dilated and congested blood vessels (V) were noticed. [H\&E, X 400].

(D) Group III (green tea group) showing a bronchiole (B) and alveoli (AL) with apparently thin interalveolar septa (black arrow). Notice cellular infiltration (white arrow) and extravasated red blood cells (arrow head). [H\&E, X400].

(E) Group IV (AV group) showing alveoli (AL) with apparently thick interalveolar septa (black arrow). Notice cellular infiltration (white arrow), extravasated red blood cells (arrow head) and congested blood vessels (V). [H\&E, X400].

(F) Group V (green tea and AV group) showing alveoli (AL), with thick interalveolar septa (black arrow). Notice cellular infiltration (white arrow), extravasated red blood cells (arrow head) and congested blood vessels (V). [H\&E, X 400].

of nuclear apoptosis). Negative cytoplasmic staining of caspase-3 was found in cytoplasm of bronchial cells, alveolar and interalveolar septatal and along the endothelial lining of blood vessels of control group (Figure 3A). In BLM group, caspase- 3 was highly expressed (Figure 3B), in green tea 
(A)

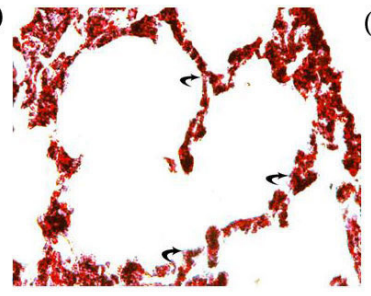

(B)

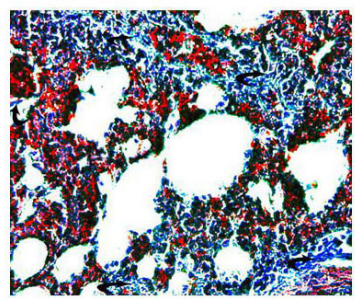

(C)

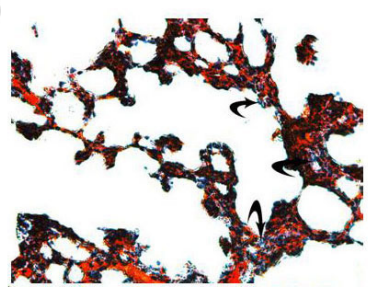

(D)

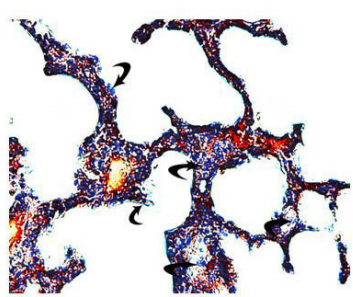

(E)

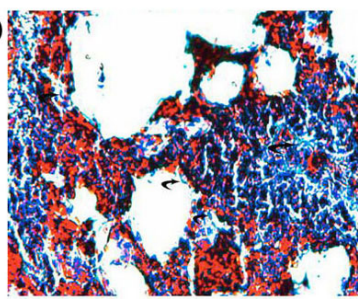

Figure 2. Photomicrograph of a section in rat lung according to masson trichrome.

(A) Control group showing very thin collagen fibers around alveoli and within the interalveolar septa (curved arrow).

(B) BLM group showing extensive accumulation of collagen fibers around alveoli and within the interalveolar septa (curved arrow).

(C) Green tea group showing minimal accumulation of collagen fibers in interalveolar septa (curved arrow).

(D) AV group showing moderate accumulation of collagen fibers in interalveolar septa (curved arrow).

(E) Green tea and AV group showing marked accumulation of collagen fibers around alveoli and bronchiole and within the interalveolar septa (curved arrow). [Masson's trichrome, $x$ 400].

group, it was mildly expressed (Figure 3C) while caspase-3 expression was moderate in AV group (Figure 3D). Group V (green tea and AV group) showed high caspase-3 expression in cytoplasm of alveolar cells (Figure 3E).

\section{Morphometric results}

The mean area \% of collagen fibers accumulation and of caspase-3 expression for all groups was represented in Tables 1 and 2) and (Histograms 1 and 2). There was a significant decreased $(\mathrm{P} \leq 0.05)$ in collagen fibers accumulation and in caspase- 3 expression in group III compared with group II (BLM group) while this decrease was insignificant in group V. Group IV showed insignificant decreased $(P \leq 0.05)$ in collagen fibers accumulation compared with group II while the decrease was significant in caspase-3 expression.

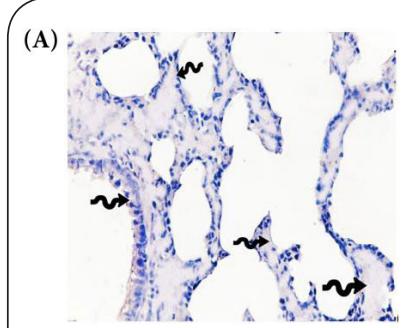

(B)
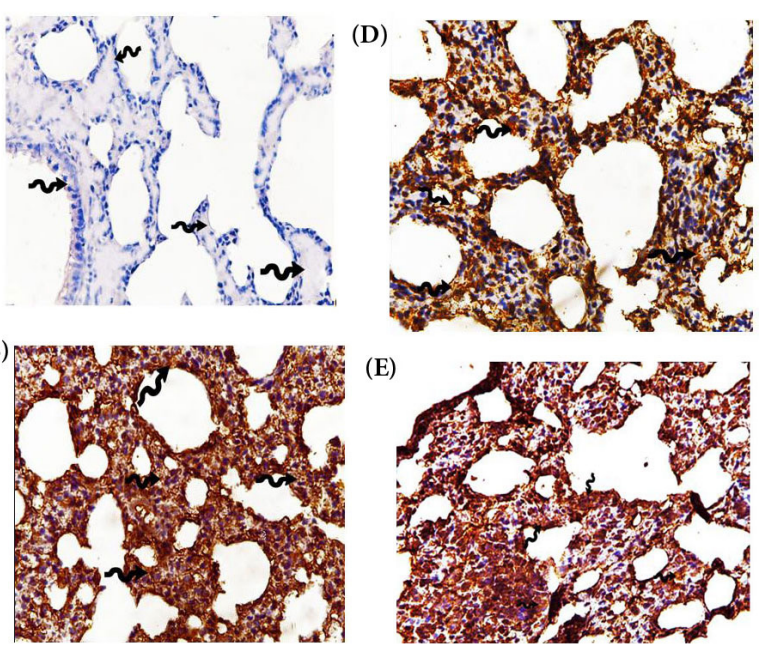

(E)

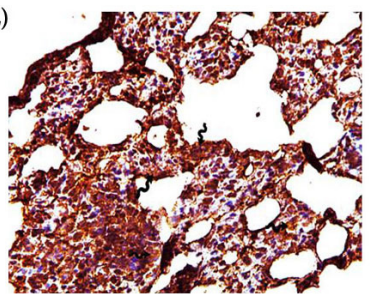

(C)

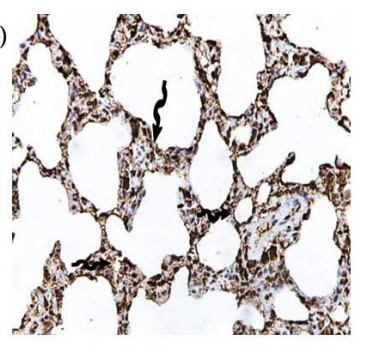

Figure 3. Photomicrograph of a section in rat lung according to immunohistochemical study.

(A) Control group showing negative caspase-3 immunostaining of cytoplasm of bronchial cells, alveolar and interalveolar septatal cells and along the endothelial lining of blood vessels (zigzag arrow).

(B) BLM group showing highly caspase-3 expression in cytoplasm of alveolar cells, septal cells and along the endothelial lining of some blood vessels (zigzag arrow). (C) Green tea group showing mild caspase-3 expression in cytoplasm of alveolar cells, septal cells and along the endothelial lining of some blood vessels (zigzag arrow). (D) AV group showing moderate caspase- 3 expression in cytoplasm of alveolar cells, septal cells and along the endothelial lining of some blood vessels (zigzag arrow).

(E) Green tea and AV group showing high caspase-3 expression in cytoplasm of alveolar cells, septal cells and along the endothelial lining of some blood vessels (zigzag arrow). [caspase-3 immunostaining X 400].

\section{Discussion}

Pulmonary fibrosis is a chronic, progressive and lethal diffuse interstitial lung disease. It has re-emerged as a focus of sci-entific study, due to its increasing incidence [23] and there has been no effective medication for this progressive disease up to now [24]. The BLM induced pulmonary fibrosis group (group II) in the present study showed thick interalveolar septa encroaching on alveoli (collapsed alveoli), cellular infiltration, dilated congested blood vessels with extravasated RBCs, extensive accumulation of collagen fibers around alveoli or within the 
Salem et al. Journal of Histology \& Histopathology 2014, http://www.hoajonline.com/journals/pdf/2055-091X-1-6.pdf

Table 1. Showing the mean area $\%$, SD of collagen fibers accumulation in groups I, II, II, IV and V. Group III, IV and V compared with group II.

\begin{tabular}{|c|c|c|c|c|c|}
\hline & Group I & Group II & Group III & Group IV & Group V \\
\hline Mean area $\%$ & $0.17 \%$ & $14.28 \%$ & $1.77 \%$ & $9.67 \%$ & $12.52 \%$ \\
\hline $\mathrm{SD} \pm$ & 0.0437 & 3.1858 & 0.6003 & 3.7466 & 1.7967 \\
\hline$P$ value & -- & -- & 0.000 & 0.063 & 0.206 \\
\hline Significance & -- & -- & S & NS & NS \\
\hline
\end{tabular}

$\mathrm{SD}=$ Standard deviation; $\mathrm{S}=$ Significant at $\mathrm{P}<0.05$;

NS=Non Significant

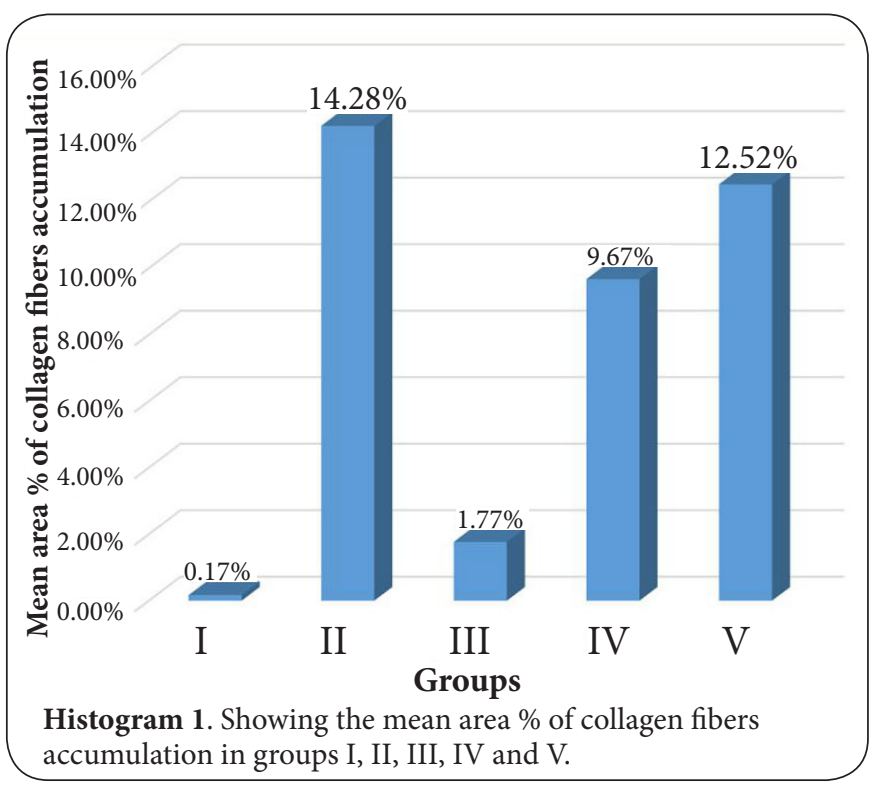

Table 2. Showing the mean area \% of caspase- 3 expression and SD in groups I, II, III, IV and V. Group III, IV and V compared with group II.

\begin{tabular}{llllll}
\hline & Group I & Group II & Group III & Group IV & Group V \\
\hline Mean area \% & 0 & 25.69 & 5.67 & 14.14 & 22.79 \\
SD \pm & 0 & 4.1012 & 0.7010 & 5.0297 & 1.0006 \\
P value & -- & -- & 0.000 & 0.002 & 0.093 \\
Significance & -- & -- & S & S & NS \\
\hline
\end{tabular}

$\mathrm{SD}=$ Standard deviation; $\mathrm{S}=$ Significant at $\mathrm{P}<0.05$;

NS=Non Significant;

interalveolar septa and highly expressed caspase-3 reaction. In agreement with these findings, some researchers reported that in BLM-induced models of pulmonary fibrosis many inflammatory cells including neutrophils and esinophils were observed in the alveoli and interstitium, alveolar cell damage, fibroblast proliferation and subsequent collagen deposition and obli-teration of the alveolar space [25-27]. Other researcher reported that bleomycin increases lung epithelial cell apoptosis

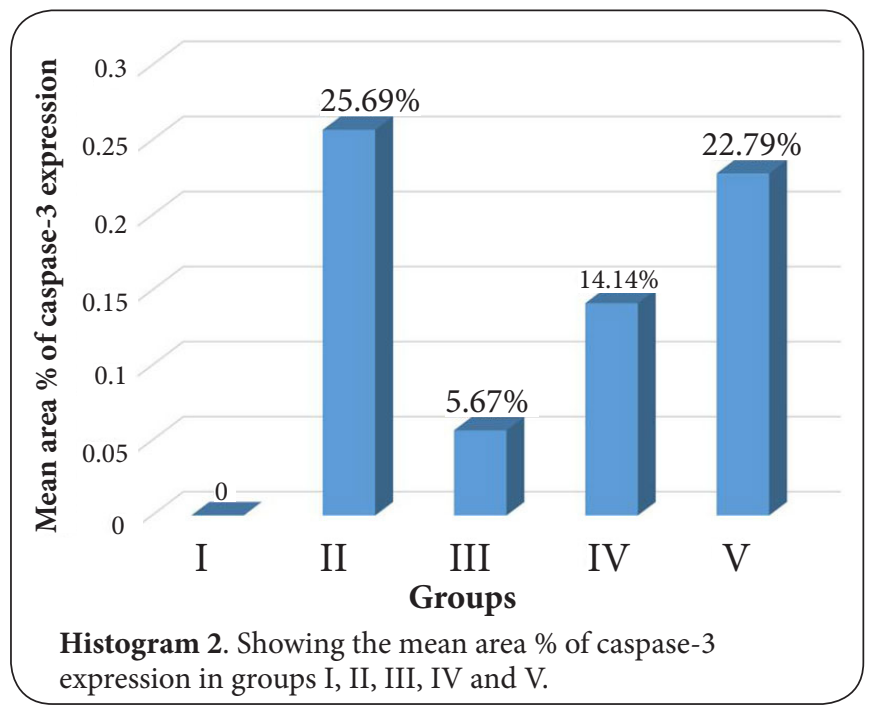

in a reactive oxygen species (ROS)-dependent manner [28]. BLM-induced pulmonary fibrosis was explained by some authors who reported that the chemotherapeutic mechanism of BLM results from the chelation of iron ions with oxygen, which leads to production of DNA-cleaving superoxide, and also hydroxide free radicals [29]. It is the increased production of ROS that lead to bleomycin's pulmonary toxicity, and may eventually lead to lung fibrosis. Also previous researches reported that reactive oxygen species have been shown to directly activate profibrotic transforming growth factor- $\beta$ (TGF- $\beta$ ) in the lung. TGF- $\beta$ promotes the development of inflammation, and increases activity at sites of inflammation, and induces the proliferation of the fibroblasts, leading to severe pulmonary fibrosis [30,31].

The green tea group (group III) in the present study showed thin interalveolar septa, few cellular infiltration and extravasated RBCs and significant decreased $(P \leq 0.05)$ in collagen fibers accumulation and in caspase- 3 expression compared with BLM group. In agreement with these findings, previous studies [18] the patchy fibrosis; also quantitative determination of hydroxyproline confirmed the reduction of collagen deposition [18]. Other studies reported that GTE constitutes an important source of antioxidants. Besides polyphenols, GTE contains additional antioxidants such as carotenoids, tocopherols (vitamin E derivatives) and vitamin C. Tea contains also minerals that function as co-factors in antioxidant enzymes: zinc, selenium and manganese. Polyphenols have additional mechanisms in which they reduce oxidation level besides direct role as antioxidants [32,33]. The antifibrotic effect of GTE explained by some authors who reported that it might be through the inhibition exerted by GTE on gelatinases involved in the damage to lung extracellular matrix, matrix metalloproteinases [18] and others have demonstrated that GTE both inhibits the signal transduction of TGF- $\beta$ by binding to transforming growth factor receptor II (TGFR) and attenuates the expression 
Salem et al. Journal of Histology \& Histopathology 2014,

http://www.hoajonline.com/journals/pdf/2055-091X-1-6.pdf

of a-smooth muscle actin (a-SMA) in MRC- 5 cells (human lung fibroblasts), which is a myofibroblast cell line, when it is stimulated by TGF- $\beta$. Myofibroblasts play crucial roles in the pathogenesis of tissue fibrosis [34].

Some scientists reported that glutathione peroxide activity, superoxide dismutase enzymes, and a phenolic antioxidant were found to be present in Aloe vera gel, which may be responsible for its antioxidant effects $[35,36]$. In spite of this, the AV group (group IV) in the present study showed alveoli with apparently thick interalveolar septa, cellular infiltration, congested blood vessels and extravasated RBCs and insignificant decreased $(P \leq 0.05)$ in collagen fibers accumulation while the decrease was significant in caspase- 3 expression compared with BLM group. These results may be explained by previous researchers who reported that high molecular weight polypeptide constituent from the AV gel as glucomannan, a mannose-rich polysaccharide, and gibberellin, a growth hormone, interact with growth factor receptor on the fibro-blast, thereby stimulating its activity and proliferation, which in turn increases collagen synthesis after topical and oral application $[35,37,38]$.

Some researchers reported that administration of multiple antioxidants could be a more effective mode used in the treatment of obstructive lung diseases [39] and others stated that herb pair which consists of two single herbs presents significantly better pharmacological efficacy than individual herbs because the synergistic interactions between the com-ponents of herbals greatly contribute to the enhancement of their therapeutic efficacy [40]. Contrary to this, group V (green tea and AV group) of the present study revealed thick inter-alveolar, collapsed alveoli, cellular infiltration, dilated congested blood vessels with extravasated RBCs and insignificant decreased $(P \leq 0.05)$ in collagen fibers accumulation and in caspase-3 expression compared with BLM group. These results may be explained by previous researches who demonstrated that there was not synergistic anti-oxidative capacity when the flavonoid compounds were used in combination and the combination of two strong antioxidants may not necessarily engender stronger efficacy, it may even produce antagonistic interaction. In contrast, when a weaker antioxidant was combined with a stronger one, the former may regenerate the latter, thus improving the overall free radical quenching capacity of the combination [41].

\section{Conclusion}

Green tea and aloe vera partially alleviate pulmonary fibrosis induced by bleomycin in rats. Supporting the potential benefits of using aloe vera and green tea as a potential novel therapeutic agents by diet.

\section{Competing interests}

The authors declare that they have no competing interests.

Authors' contributions
\begin{tabular}{|l|c|c|c|}
\hline Authors' contributions & MYS & NEE & EMF \\
\hline Research concept and design & $\checkmark$ & -- & -- \\
\hline Collection and/or assembly of data & -- & $\checkmark$ & -- \\
\hline Data analysis and interpretation & $\checkmark$ & $\checkmark$ & $\checkmark$ \\
\hline Writing the article & $\checkmark$ & -- & $\checkmark$ \\
\hline Critical revision of the article & $\checkmark$ & $\checkmark$ & $\checkmark$ \\
\hline Final approval of article & $\checkmark$ & $\checkmark$ & $\checkmark$ \\
\hline Statistical analysis & $\checkmark$ & -- & -- \\
\hline
\end{tabular}

Publication history

EIC: Giuseppe Musumeci, University of Catania, Italy.

Received: 28-Jun-2014 Final Revised: 23-Jul-2014

Accepted: 06-Aug-2014 Published: 30-Aug-2014

\section{References}

1. Kapoor VK, Dureja J and Chadha R. Herbals in the control of ageing. Drug Discov Today. 2009; 14:992-8. | Article I PubMed

2. Kim HR, Rajaiah R, Wu QL, Satpute SR, Tan MT, Simon JE, Berman BM and Moudgil KD. Green tea protects rats against autoimmune arthritis by modulating disease-related immune events. J Nutr. 2008; 138:2111-6. | Article | PubMed Abstract | PubMed Full Text

3. Sundaram R, Naresh R, Shanthi P and Sachdanandam P. Modulatory effect of green tea extract on hepatic key enzymes of glucose metabolism in streptozotocin and high fat diet induced diabetic rats. Phytomedicine. 2013; 20:577-84. I Article I PubMed

4. Chacko SM, Thambi PT, Kuttan R and Nishigaki I. Beneficial effects of green tea: a literature review. Chin Med. 2010; 5:13. I Article I PubMed Abstract | PubMed Full Text

5. Rodriguez Rodriguez E, Darias Martin J and Diaz Romero C. Aloe vera as a functional ingredient in foods. Crit Rev Food Sci Nutr. 2010; 50:305-26. | Article I PubMed

6. Abd-Alla HI, Shaaban M, Shaaban KA, Abu-Gabal NS, Shalaby NM and Laatsch H. New bioactive compounds from Aloe hijazensis. Nat Prod Res. 2009; 23:1035-49. | Article | PubMed

7. Boghani A.H, Raheem A and Hashmi S.I. Development and Storage Studies of Blended Papaya-Aloe vera Ready to Serve (RTS) Beverage. J. Food Process Technol. 2012; 3:185. I Article

8. Rouissi K, Kouidhi S, Hamrita B, Ouerhani S, Cherif M and Elgaaied AB. Therapeutic Effects of Aloe Vera Plant Extract Against Cyclophosphamide and Buthionine Sulfoximine Induced Toxicities in the Bladder. Biochem. Pharmacol. 2012; 1:101.

9. Tabolacci C, Lentini A, Mattioli P, Provenzano B, Oliverio S, Carlomosti F and Beninati $S$. Antitumor properties of aloe-emodin and induction of transglutaminase 2 activity in B16-F10 melanoma cells. Life Sci. 2010; 87:316-24. | Article I PubMed

10. Im SA, Lee YR, Lee YH, Lee MK, Park YI, Lee S, Kim K and Lee CK. In vivo evidence of the immunomodulatory activity of orally administered Aloe vera gel. Arch Pharm Res. 2010; 33:451-6. | Article I PubMed

11. Moniruzzaman M, Rokeya B, Ahmed S, Bhowmik A, Khalil MI and Gan SH. In vitro antioxidant effects of Aloe barbadensis Miller extracts and the potential role of these extracts as antidiabetic and antilipidemic agents on streptozotocin-induced type 2 diabetic model rats. Molecules. 2012; 17:12851-67. | Article | PubMed

12. D’Alessandro-Gabazza CN, Kobayashi T, Boveda-Ruiz D, Takagi T, Toda M, Gil-Bernabe P, Miyake Y, Yasukawa A, Matsuda Y and Suzuki N et al. Development and preclinical efficacy of novel transforming growth factor-beta1 short interfering RNAs for pulmonary fibrosis. Am J Respir Cell Mol Biol. 2012; 46:397-406. | Article | PubMed

13. Gao Y, Lu J, Zhang Y, Chen Y, Gu Z and Jiang X. Baicalein attenuates bleomycin-induced pulmonary fibrosis in rats through inhibition of miR- 
Salem et al. Journal of Histology \& Histopathology 2014,

21. Pulm Pharmacol Ther. 2013; 26:649-54. | Article | PubMed

14. Hecker L, Vittal R, Jones T, Jagirdar R, Luckhardt TR, Horowitz JC, Pennathur S, Martinez FJ and Thannickal VJ. NADPH oxidase-4 mediates myofibroblast activation and fibrogenic responses to lung injury. Nat Med. 2009; 15:1077-81. | Article | PubMed Abstract | PubMed Full Text

15. Kliment $C R$ and Oury TD. Oxidative stress, extracellular matrix targets, and idiopathic pulmonary fibrosis. Free Radic Biol Med. 2010; 49:70717. | Article | PubMed

16. Madala SK, Schmidt S, Davidson C, Ikegami M, Wert S and Hardie WD. MEK-ERK pathway modulation ameliorates pulmonary fibrosis associated with epidermal growth factor receptor activation. $\mathrm{Am} J$ Respir Cell Mol Biol. 2012; 46:380-8. | Article | PubMed Abstract | PubMed Full Text

17. El-Gamal MA, Zaitone SA and Moustafa YM: Role of irbesartan in protection against pulmonary toxicity induced by bleomycin in rats. IOSR Journal Of Pharmacy. 2013; 3:38-47. I Pdf

18. Hamdy MA, El-Maraghy SA and Kortam MA. Modulatory effects of curcumin and green tea extract against experimentally induced pulmonary fibrosis: a comparison with $\mathbf{N}$-acetyl cysteine. J Biochem $\mathrm{Mol}$ Toxicol. 2012; 26:461-8. | Article | PubMed

19. Ramachandraiahgari RMY, Somesula SR, Adi PJ, Mannur IS, Enamala $\mathrm{M}$ and Matcha B. Protective role of ethanolic extract of aloe vera antioxidant properties on liver and kidney of streptozotocin-induced diabetic rats. Digest Journal of Nanomaterials and Biostructures. 2012; 7:175-184. | Article

20. Bancroft JD and Layton C: The Hematoxylin and eosin. In: Suvarna SK, Layton C and Bancroft JD editors. Theory \& Practice of histological techniques. $7^{\text {th }}$ ed., Churchill Livingstone of El Sevier. Philadelphia. Ch. 10 and 11. 2013; $172-214$.

21. Jackson $P$ and Blythe D: Immunohistochemical techniques. In: Suvarna SK, Layton C and Bancroft JD editors. Theory \& Practice of histological techniques. 7th ed., Churchill Livingstone of El Sevier. Philadelphia. Ch. 18. 2013; 381 - 434.

22. Bayomy NA, Abd-Elmagyed ER and Tawfik SM. Effect of Leflunomide (Avara) Drug on the Lung of Adult Male Albino Rats: A Histological and Immunohistochemical Study. Egypt J. Histol. 2008; 31:278-282. | Pdf

23. Liu X, Qian L, Nan H, Cui M, Hao X and Du Y. Function of the transforming growth factor-beta1/c-Jun $\mathrm{N}$-terminal kinase signaling pathway in the action of thalidomide on a rat model of pulmonary fibrosis. Exp Ther Med. 2014; 7:669-674. | Article | PubMed Abstract | PubMed Full Text

24. Khodayar MJ, Kiani M, Hemmati AA, Rezaie A, Zerafatfard MR, Nooshabadi MRR and Goudarzi M. The Preventive Effect of Atorvastatin on Paraquat-Induced Pulmonary Fibrosis in the Rats. Advanced Pharmaceutical Bulletin. 2014; 4:345-349.

25. Cao H, Zhou X, Zhang J, Huang X, Zhai Y, Zhang X and Chu L. Hydrogen sulfide protects against bleomycin-induced pulmonary fibrosis in rats by inhibiting NF-kappaB expression and regulating Th1/Th2 balance. Toxicol Lett. 2014; 224:387-94. | Article | PubMed

26. Finch PW, Mark Cross LJ, McAuley DF and Farrell CL. Palifermin for the protection and regeneration of epithelial tissues following injury: new findings in basic research and pre-clinical models. J Cell Mol Med. 2013; 17:1065-87. | PubMed

27. Wan YY, Tian GY, Guo HS, Kang YM, Yao ZH, Li XL, Liu QH and Lin DJ. Endostatin, an angiogenesis inhibitor, ameliorates bleomycin-induced pulmonary fibrosis in rats. Respir Res. 2013; 14:56 | Article | PubMed Abstract | PubMed Full Text

28. Day BJ. Antioxidants as potential therapeutics for lung fibrosis. Antioxid Redox Signal. 2008; 10:355-70. | Article | PubMed Abstract | PubMed Full Text

29. Lawrenz J, Herndon B, Kamal A, Mehrer A, Dim DC, Baidoo C, Gasper D, Nitz J, Molteni A and Baybutt RC. Dietary Flaxseed Oil Protects against Bleomycin-Induced Pulmonary Fibrosis in Rats. Pulm Med. 2012; 2012:457031. | Article | PubMed Abstract | PubMed Full Text

30. Shi K, Jiang J, Ma T, Xie J, Duan L, Chen R, Song P, Yu Z, Liu C, Zhu Q and Zheng J. Pathogenesis pathways of idiopathic pulmonary fibrosis in bleomycin-induced lung injury model in mice. Respir Physiol Neurobiol. 2014; 190:113-7. | Article | PubMed

31. Kliment CR and Oury TD. Oxidative stress, extracellular matrix targets, and idiopathic pulmonary fibrosis. Free Radic Biol Med. 2010; 49:70717. | Article | PubMed

32. Giménez B, López de Lacey A, Pérez-Santín E, López-Caballero ME and Montero P. Release of active compounds from agar and agaregelatin films with green tea extract. Food Hydrocolloids. 2013; 30:264-271. | Article

33. Narotzki B, Reznick AZ, Aizenbud D and Levy Y. Green tea: a promising natural product in oral health. Arch Oral Biol. 2012; 57:429-35. | Article I PubMed

34. Tabuchi M, Hayakawa S, Honda E, Ooshima K, Itoh T, Yoshida K, Park A, Higashino $\mathrm{H}$, Isemura $\mathrm{M}$ and Munakata $\mathrm{H}$. Epigallocatechin-3-gallate suppresses transforming growth factor-beta signaling by interacting with the transforming growth factor-beta type II receptor. World J. Exp. Med. 2013; 3:100-107.

35. Sajjad A and Sajjad SS. Aloe vera: An Ancient Herb for Modern Dentistry: A Literature Review. Journal of Dental Surgery. 2014.

36. Ibe C, Jacobs CC, Imo C, Osuocha KU and Okoronkwo MU. Evaluation of the Antioxidant Activities of Psidium guajava and Aloe vera. British Journal of Pharmaceutical Research. 2014; 4:397-406. | Article

37. Surjushe A, Vasani R and Saple DG. Aloe vera: a short review. Indian J Dermatol. 2008; 53:163-6. | Article | PubMed Abstract | PubMed Full Text

38. Anshoo G, Singh S, Kulkarni AS, Pant SC and Vijayaraghavan R. Protective effect of Aloe vera L. gel against sulphur mustard-induced systemic toxicity and skin lesions. Indian Journal of Pharmacology. 2005; 37:103110. | Article

39. Biswas S, Hwang JW, Kirkham PA and Rahman I. Pharmacological and dietary antioxidant therapies for chronic obstructive pulmonary disease. Curr Med Chem. 2013; 20:1496-530. | Article | PubMed

40. Yang WJ, Li DP, Li JK, Li MH, Chen YL and Zhang PZ. Synergistic antioxidant activities of eight traditional Chinese herb pairs. Biol Pharm Bull. 2009; 32:1021-6. | Article | PubMed

41. Wang F, Zhao S, Li F, Zhang B, Qu Y, Sun T, Luo T and Li D. Investigation of antioxidant interactions between Radix Astragali and Cimicifuga foetida and identification of synergistic antioxidant compounds. PLOS One. 2014; 9:e87221. | Article | PubMed Abstract | PubMed Full Text

Citation:

Salem MY, El-Azab NE-E and Faruk EM. Modulatory effects of green tea and aloe vera extracts on experimentally-induced lung fibrosis in rats: histological and immunohistochemical study. J Histol Histopathol. 2014; 1:6. http://dx.doi.org/10.7243/2055-091X-1-6 